\title{
Development and Initial Validation of The Russian Version of The RAADS-14: A Self-Report Questionnaire to Assess Autistic Traits
}

\author{
Ivan Skorokhodov \\ Rehabilitation Center for Children with ASD "Our Sunny World" \\ Ksenia Vergeles \\ Rehabilitation Center for Children with ASD "Our Sunny World" \\ Elena Skorokhodova \\ Russian State Social University \\ Svetlana Firsova \\ Volga State University of Technology

\section{Galina Portnova} \\ Institute of Higher Nervous Activity and Neurophysiology \\ Anton Varlamov ( $\square$ antonvarlamov@gmail.com ) \\ Pushkin State Russian language Institute
}

\section{Research Article}

Keywords: RAADS-14, autistic traits, Russian-speaking population, anecdotal evidences

Posted Date: November 25th, 2020

DOI: https://doi.org/10.21203/rs.3.rs-109635/v1

License: (c) (i) This work is licensed under a Creative Commons Attribution 4.0 International License. Read Full License 


\section{Abstract}

The aim of our research was to construct and validate a Russian version of the RAADS-14 (the RAADS-14 Rus), a brief self-report questionnaire designed for assessment of autistic traits, to provide a reference point in developing autism self-assessment tools in Russian-speaking population. The data were collected for 1724 participants, including a general sample of non-psychiatric young adults $(n=849)$ and adults with ASD $(n=49)$. Confirmatory factor analysis revealed that the RAADS-14 Rus has the same factor structure as the original Swedish version yielding acceptable fit indices. The discriminating properties, however, were substantially worse than in the original study (AUC = .92 vs .99); it stems from higher mean RAADS-14 scores for the Russian control sample vs the original controls (mean $=13.9$ vs 3.9) confirming prior anecdotal evidences of greater mean scores yielded by international ASD assessment tools on Russian-speaking populations. The correlations between the RAADS-14 Rus domain scores and the Big Five factors were similar to previously obtained findings.

The results of the study indicate that the RAADS-14 Rus can be used for assessment of autistic traits and, with some reservations, as an ASD screening tool for adult Russian-speaking population. Further research is necessary to develop more precise screening tools.

\section{Introduction}

\section{RAADS-14 as a screening tool for autism spectrum disorders in adult population}

Autism spectrum disorder (ASD) is a range of neurodevelopmental conditions characterized by persisting deficits in social communication and interaction, repetitive and stereotyped behavior, and restricted interests ${ }^{1}$. The prevalence of ASD in adult population is steadily increasing, it greatly affects the quality of life of adults with ASD and impairs a significant burden on health and social care ${ }^{2}$. Autism in adults with no intellectual impairments is also quite frequent ${ }^{3}$, and often underdiagnosed ${ }^{4}$, particularly in women ${ }^{5}$. Late identification and general underdiagnosis and misdiagnosis of ASD leads to a problem of 'a lost generation' of autistic adults with no intellectual impairments ${ }^{6}$. The comorbidity of ASD and other neuropsychiatric conditions is quite high ${ }^{7}$, differential diagnostics can also pose a problem, therefore proper assessment of autistic traits and related problems can be crucial for increasing the quality of life of people with ASD ${ }^{8}$. There is a range of self-report questionnaires available for screening of ASD in adults with no intellectual impairments, the most widely used being: the Autism-Spectrum Quotient (AQ, 50 items) ${ }^{9}$ and its shorter versions, AQ-1. AQ-2. and AQ-J-21 10; the Ritvo Asperger and Autism Diagnostic Scale - Revised (RAADS-R, 80 items) ${ }^{11}$ and its short version RAADS-14 ${ }^{8}$; the Social Responsiveness Scale, 2nd edition -Adult form

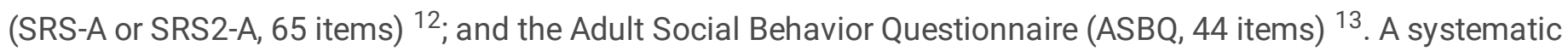
review found that stronger evidence of good or satisfactory measurement and diagnostic properties exist for AQ-5. AQ-S, and RAADS-R and RAADS- $14^{10}$.

The RAADS-14 is a 14-item self-report questionnaire specifically designed to be used as a screening tool for ASD and distributed under CC BY 2.0 Creative Commons License ${ }^{8}$. It was developed on the basis of the longer and more comprehensive RAADS-R, which has demonstrated good overall psychometric properties, test-retest reliability, discriminant and convergent validity, sensitivity and specificity $11,14,15$. The RAADS-14 was developed using the Swedish version of the RAADS-R ${ }^{16}$ and validated on Swedish clinical and non-clinical samples. According to the reported factor structure, the RAADS-14 consists of three factors corresponding to domains of Mentalizing deficits, Social anxiety and Sensory reactivity. All the items are scored on a four-point Likert scale (ranging from 0 to 3 ) indicating duration of each symptom ( 3 = 'true now and when I was young', 2 = 'true only now', 1 = 'true only when I 
was younger than 16 ' and $0=$ 'never true'). Item scores are summed to produce the total score and the subscale scores. The recommended cutoff of 14 for the original English version yielded excellent sensitivity of 0.97 and specificity of 0.95 over non-psychiatric population. The gender differences were moderate: neurotypical males scoring somewhat higher than females in the mentalizing deficits and social anxiety domains, while females scored higher than males in the sensory reactivity domain.

The RAADS-14 is very short and easy to administer and has already demonstrated the potential to distinguish efficiently between ASD and other neuropsychiatric conditions in adult population.

\section{Assessing autistic traits in adult population in Russia: current problems and possible directions}

The situation with clinical diagnostics of ASD in adult population in Russia is very problematic, as several historical factors add to the above-mentioned diagnostic issues leading to even greater ASD underdiagnosis in Russian adult population. According to the official statistical data by Rosstat (Russian statistical agency), in 2016 there were only 96 adults officially diagnosed as having ASD (less than $.001 \%$ of adult population) ${ }^{17}$, which is at least 1000 times less than the estimates based on European cohort statistics. This huge disagreement reveals the fact that it was virtually impossible to get an official diagnosis of ASD for high functioning adolescents and adults for two major reasons. The first reason is related to underdiagnosis of ASD in childhood during 1970-2010s which was less pronounced than for adults but still quite prominent: as of 1999, the officially recognized ratio was 1 in $385^{18}$. For children without intellectual impairments the diagnosis was almost never officially established, often in order to help the parents to avoid the stigma ${ }^{19}$. The second reason is an almost routine obligatory change of the official clinical diagnosis from ASD to some other neuropsychiatry condition performed when a person reaches adolescence or adulthood, most commonly, to schizoaffective disorder and/or mental retardation, this clinical practice was officially reproved only on the June $30^{\text {th }}, 2014^{20}$. On the October $4^{\text {th }}, 2017$, Russian Ministry of Health issued a letter of instructions (№ 17-1/10/1-6371) explicitly prohibiting an unfounded change of diagnosis from ASD to another mental condition for individuals reaching adulthood, as some psychiatrists tended to adhere to the old diagnosisswitching practice ${ }^{21}$. Due to the efforts of governmental and non-governmental institutions, autism professionals, parental community, and autism community it is now widely recognized that ASD in adults is currently underdiagnosed in Russia but implementing the diagnostic routines will have to take some time, and is hindered by the lack of diagnostic tools and trained professionals. The Russian version of ADOS-2 was published only in 2016 22,23 , and its adult module still remains under validation.

In this situation, the need for self-assessment tools in the autistic community has long been perceived as high. Despite that, to our best knowledge, no self-assessment tools for evaluating autistic traits and for screening of ASD in adult population or adolescents has been officially developed, adapted, and validated on Russian-speaking samples. Several attempts were made by members of autistic community to provide Russian versions of internationally recognized questionnaires, even if just for a rough reference; the largest collection of unofficial translations (including AQ, RAADS-R, Aspie Quiz, and The Broad Autism Phenotype Test) is presented at a web-site related to autism and to the problems of people with ASD $^{24}$ developed and maintained by members of Russian autism community. There are multiple anecdotal pieces of evidence that most of these questionnaires used with cutoffs established for European samples tend to overestimate the prominence of autistic traits but no data on this issue have been officially reported.

The lack of ASD diagnostic tools and inventories assessing autistic traits validated on Russian-speaking samples significantly limits the options to assess criterion validity of any emerging ASD screening questionnaire. In order to 
get additional circumstantial evidence, special efforts could be made to evaluate the questionnaire's discriminant validity comparing it to other personality trait inventories. There are numerous studies exploring the links between the autism traits and other personality factors and constructs. The Big Five personality model is probably the most well-established general personality construct ${ }^{25}$ which was found to strongly relate to autism traits in a large number of studies, consistently revealing moderate positive correlations of ASD scores to neuroticism, and weak to moderate negative correlations to all the other Big Five factors ${ }^{26}$. A study utilizing multivariate approaches to explore the relations between IPIP-NEO-120 and RAADS-R scores found that Big Five personality factors accounted for $70 \%$ of variance in autism trait scores ${ }^{27}$. These findings suggest that a Big Five personality questionnaire would be a good tool to assist in affirming convergent and discriminant validity of an ASD assessment tool.

\section{Aim and general design of the study}

The general aim of our research was to construct and validate a Russian version of the RAADS-14 (the RAADS-14 Rus) to provide the initial reference point in developing the body of instruments for assessing autistic traits in Russian-speaking adult population. This measure was chosen due to its good psychometric characteristics, discriminative properties, and simplicity of use. The study aims to assess the reliability of the RAADS-14 Rus, its factor structure, and to provide the initial estimates of the questionnaire's validity, diagnostic properties, and potential for use as a screening tool for ASD in adults with no intellectual impairments. We have also formulated three specific research hypotheses:

1. The RAADS-14 Rus factor structure would be equivalent or similar to the factor structure of the original Raads14 ;

2. The RAADS-14 Rus total scores and subscale scores will have weak to moderate correlations to the scores of the Big Five personality factors, in particular, positive to neuroticism and negative to extraversion, consistent to the previous studies;

3. The distribution of the RAADS-14 scores could be different for general Russian-speaking population, producing greater mean total score values and yielding potentially higher cutoff scores to provide reasonable specificity of the questionnaire.

\section{Results}

\section{Reliability and the factor structure}

Cronbach's a for the 14 items of the RAADS-14 Rus was 0.839 demonstrating good reliability of the questionnaire with an average inter-item correlation of 0.272 .

CFA performed for a three-factor model reflecting subscale item composition of the original RAADS-14 (Fig 1) revealed acceptable fit indices (RMSEA $\left.=.067, \mathrm{CFI}=.954, \mathrm{df}=91, \chi^{2}=12076.025, \mathrm{p}<.0001\right)$. CFI demonstrating a good fit ${ }^{28}$ and RMSEA demonstrating a moderately good fit ${ }^{29}$. All the factor loads were above .42 . The data suggest that the factor structure of the RAADS-14 Rus is very similar to the factor structure of the original Swedish version, therefore the three domains (Mentalizing deficits, Social anxiety, and Sensory reactivity) of the RAADS-14 RUS were scored as in the original version.

\section{Distribution of scores and discriminative properties}


The distributions of total RAADS-14 Rus scores in non-psychiatric young adults $(n=794$, mean $=13.9, S D=7.5$, median $=13)$, and ASD participants $(n=49$, mean $=29.3, S D=8.7$, median $=30.5)$ are shown at Figure 2. The score distribution in non-psychiatric young adults, as expected, was skewed to the left, while the score distributions for self-diagnosed and clinically diagnosed adults with ASD were very similar and were skewed to the right, with no prominent ceiling effects observed for any of the samples. An additional comparison revealed that the RAADS-14 Rus scores of ASD participants with ADOS-2 verified diagnosis were slightly higher $(n=13$, mean $=33.2, S D=7.1$, median $=35.0)$ than the scores of the rest of ASD participants but the difference was not statistically significant (U= $170.5, p=0.150$ ). The distribution of scores for the ASD participants was similar to the data obtained with the RAADS-14 for Swedish ASD population ${ }^{8}$. The distribution of the RAADS-14 Rus scores for the non-psychiatric adults was less extremely skewed to the left compared to the Swedish data, producing much greater mean and median (13.9 and 13 vs. 3.9 and 3), confirming our prediction that mean RAADS-14 Rus scores are expected to be higher than the original scores. The comparison of the domain scores between the non-psychiatric participants (Sample 1, $n=794)$ and the participants with clinically established ASD diagnosis $(n=49)$ revealed very robust effects $\left(U_{M D}=4773, p_{\text {two-tailed }}<.0001 ; U_{S R}=8404,5, p_{\text {two-tailed }}<.0001 ; U_{S A}=3685,5, p_{\text {two-tailed }}<.0001\right)$ indicating that the ASD participants scored higher on each domain compared to the non-psychiatric participants.

A ROC curve comparing the results of non-psychiatric young adults and participants with ASD diagnosis yielded an AUC of 0.92, evidencing reasonably good discriminative properties of the RAADS-14 Rus.

The operating characteristics of the RAADS-14 Rus are shown at Figure 3. The originally suggested cutoff of 14 points and above would yield a sensitivity of $93.9 \%$ and a specificity of $56.4 \%$; a cutoff of 22 points and above would yield a sensitivity of $85.7 \%$ and a specificity of $85.4 \%$.

\section{Age and Gender differences}

Considering large difference in mean age and in the RAADS-14 Rus scores between the samples, the assessment of possible relations between age and the RAADS-14 Rus total scores was performed separately for all the samples and, additionally, for the participants with ASD pooled across the samples. A significant negative correlation with age was observed for Sample $2\left(n=509, r=-.32\right.$, $\left.p_{\text {two-tailed }}<.001\right)$ but not for Sample $1\left(n=793, r=-.017\right.$, $p_{\text {two- }}$

tailed $=.629)$ and Sample $3\left(n=364, r=-.1, p_{\text {two-tailed }}=.058\right)$. This correlation was not significant for the ASD subgroup $(n=49, r=-.13, p=.388)$.

The gender differences were also assessed separately for all the samples and for the participants with ASD. The participants who reported their gender as 'other' (Sample $2 n=20$; Sample $3 n=16$ ) were characterized by significantly higher RAADS-14 Rus total scores than the participants stating their gender as both male or female for Sample 2 (H $(2, N=509)=3.92, p<.001)$ and for Sample $3(H(2, N=364)=10.4 . p=.006)$ (see Table 1). There were no significant differences between the males and the females in the RAADS-14 Rus total scores for any of the samples, nor for the ASD subgroups.

The RAADS-14 Rus domain score comparison for males and females in the non-psychiatric population revealed that, similarly to the RAADS-14 validation study, females scored higher than males for Sensory reactivity domain (females: Mean = 4.12, SD = 2.35; males: Mean = 3.29, SD = 2.44; U= 5815.5, $\mathrm{p}<.0001$ ). No significant differences were found between males and females for Mentalizing deficits and Social anxiety domains of the RAADS-14 Rus (U $=71851,5, p=.87$ and $U=68964,5, p=.27$ ).

\section{Correlations with Big Five personality traits}


The correlations of the RAADS-14 Rus total scores and domain scores with the Big Five personality factors are given in Table 1. The total score yielded moderate positive correlations with Neuroticism (.45), moderate negative correlation with Extraversion (-.49), and weak but significant negative correlations with the other Big Five factors. Social mentalizing and Social anxiety domains each yielded similar correlation patterns, while Sensory and cognitive perception domain had weaker correlations with the Big Five facets reaching significance only for Neuroticism and Extraversion.

Table 1. The correlations between the RAADS-14 Rus total scores and subscores, and the Big Five personality factors, significant correlations are given in bold.

\begin{tabular}{|lllllllll|}
\hline Big Fivetraits & $\begin{array}{l}\text { RAADS-14 } \\
\text { Rus Total }\end{array}$ & $p$ & $\begin{array}{l}\text { Mentalizing } \\
\text { deficits }\end{array}$ & $p$ & $\begin{array}{l}\text { Sensory } \\
\text { reactivity }\end{array}$ & $p$ & $\begin{array}{l}\text { Social } \\
\text { anxiety }\end{array}$ & $p$ \\
\hline $\begin{array}{l}\text { Neuroticism } \\
\text { (n=325) }\end{array}$ & .45 & $>.00001$ & .34 & $>.00001$ & .24 & .00002 & .42 & $>.00001$ \\
\hline $\begin{array}{l}\text { Extraversion } \\
\text { (n=325) }\end{array}$ & -.46 & $>.00001$ & -.32 & $>.00001$ & -.19 & .00068 & -.53 & $>.00001$ \\
$\begin{array}{l}\text { Openness to } \\
\text { experience } \\
\text { (n=325) }\end{array}$ & -.13 & .01784 & -.18 & .00105 & .019 & .73239 & -.11 & .05493 \\
\hline $\begin{array}{l}\text { Agreeableness } \\
\text { (n=325) }\end{array}$ & -.17 & .00226 & -.15 & .00817 & -.06 & .29733 & -.18 & .00125 \\
\hline $\begin{array}{l}\text { Conscientiousness } \\
\text { (n=325) }\end{array}$ & -.23 & .00004 & -.16 & .004176 & -.09 & .11757 & -.25 & .00004 \\
\hline
\end{tabular}

\section{Discussion}

\section{Reliability, validity, and discriminative properties of the RAADS-14 Rus}

The aim of this study was to develop a Russian version of the RAADS-14 (the RAADS-14 Rus) and to assess its reliability, factor structure, validity and discriminative properties. The RAADS-14 Rus has exactly the same item composition as the original version; confirmatory factor analysis (CFA) revealed that all the model fit indices were reasonably good, suggesting that the factor structure of the Russian version is equivalent to the original version ${ }^{8}$. There was a very robust difference in the scores of all the RAADS-14 Rus screening domains between the nonpsychiatric population and the ASD sample, further confirming construct validity of the RAADS-14 Rus.

The original RAADS-14 was composed of the items yielding the highest discriminative properties for ASD diagnosis; owing to this approach, the questionnaire was characterized by excellent discriminative properties at distinguishing between ASD participants and non-psychiatric controls $(A U C=.99)$ and by good discrimination between ASD and other neuropsychiatric conditions. The total RAADS-14 Rus score has good discriminative properties for distinguishing between ASD participants and general population control sample (AUC of .92), that are still not nearly as good as in the original study. This difference can be best attributed to the fact that mean RAADS-14 scores were much higher for the Russian sample than for the original Swedish sample, particularly for non-psychiatric controls. At the moment we would recommend using a provisional cutoff of 22 points and above. This cutoff yields a good sensitivity of $85.7 \%$ and a specificity of $85.4 \%$. While, taken per se, these discriminative properties can be considered operational, it should be noted that using the RAADS-14 Rus as a screening tool with this cut-off would yield a rather 
low positive predictive value, given the estimated prevalence of high functioning forms of ASD. Using an official prevalence estimate of high functioning autism of $1 / 200$ for Russian samples ${ }^{18}$, the positive predictive value would be as low as $2.9 \%$. Still, at the moment, with no other validated ASD assessment tools available for Russianspeaking population, we suggest that one may use RAADS-14 Rus for screening if all the above-mentioned considerations are taken into account. Further research is sought to develop more sensitive autism assessment tools specifically for Russian-speaking samples.

While this paper was in preparation, the results of another recent study assessing the RAADS-14 properties for a New Zealand national sample were published ${ }^{30}$. The two studies are similar in their purpose and design, and there are notable similarities in the results as well. In the both studies the mean RAADS-14 scores for non-ASD groups were much higher than in the original study (Russia 13.9, New Zealand 9.85 vs Sweden 3.9); this, combined with other possible factors, led to substantial worsening of the discriminative properties of the questionnaire. The mean RAADS-14 scores were the highest for the Russian study; it confirms our first specific prediction stemming from prior anecdotal evidences that pilot non-validated versions of autism assessment self-report questionnaires produce higher scores for Russian samples than for Western European and American samples. The underlying reasons for this effect are yet unclear; several factors may contribute but at this moment we would suggest that this difference should be largely attributed to culture-specific biases in self-reporting and speaking about one's problems and social competences rather than to elevated autistic traits in Russian neurotypical population. Despite that, the RAADS-14 performed somewhat better in this Russian study than in the New Zealand study, producing acceptable model fit indices and better specificity for the author-suggested cut-offs.

\section{Age and Gender differences}

The RAADS-14 Rus total score revealed that for one of the three samples used in this study a negative correlation of the total scores of the RAADS-14 was observed; it is consistent with the previous data indicating that different facets of autistic traits in adults tend to somewhat decrease with age ${ }^{3132}$. The female to male differences in the RAADS-14 Rus scores were quite minor and generally similar to data from the original RAADS-14 validation study collected for Swedish samples ${ }^{8}$. In our study a significant part of subjects in Samples 2 and 3 indicated their gender as 'other' or non-binary (total $n=36$ ). The non-binary participants scored significantly higher than the males and females; this also corresponds to the prior findings in other national samples showing that non-binary individuals often report elevated levels of autistic traits ${ }^{33-35}$.

\section{The RAADS-14 Rus and the Big Five personality model}

The correlations of the Big Five personality traits with the total RAADS-14 Rus score, taken as a general measure of autistic traits, were highly consistent with the earlier findings ${ }^{36}$, revealing moderate positive correlations with Neuroticism, moderate negative correlation with Extraversion, and weaker negative correlations with Agreeableness, Openness to experience, and Conscientiousness, similarly to a study using RAADS-R and IPIP-NEO-120 ${ }^{37}$. These results support good discriminative validity of the RAADS-14 Rus and confirm our prediction that the character of the relation between autistic traits, as measured by the RAADS-14 Rus, and the Big Five personality traits for the Russian sample is similar to such relation for other national populations. It can serve as a circumstantial evidence of criterion validity of the RAADS-14 Rus.

\section{Limitations and future directions}


The main limitations of the study stem from the lack of validated ASD assessment tools currently available in Russian and from very high estimates of underdiagnosis of ASD in Russian adults with no intellectual impairments. Due to our limited options to assess concurrent validity of the RAADS-14 Rus and to the limited size of the ASD sample in this study (particularly, to the small number of participants with ADOS-verified diagnosis) all the estimates of the discriminative properties of the RAADS-14 Rus should be interpreted strictly as preliminary. These findings require further validation on larger clinical and non-clinical samples. However, considering that

a. to our best knowledge, the RAADS-14 Rus is the first self-assessment inventory addressing autistic traits in adults with no intellectual impairments, and

b. the non-psychiatric sample of young adults is relatively large and represents several Russian regions, the data were collected with high consent rate and can be considered a satisfactory initial approximation of the age cohort, at least for larger cities ${ }^{38}$,

the RAADS-14 Rus can become one of the first stepping-stones in establishing a comprehensive system of ASD assessment and diagnostics for adult Russian-speaking population.

Further efforts should be made to ensure better screening sensitivity and may lead to development of new screening instruments based on larger initial pools of ASD-related items and using item selection centered around single-item discriminatory power, similarly to the process used for developing the original RAADS-14.

\section{Methods}

\section{Participants and Procedure}

A total of 1724 adults have agreed to voluntarily participate in the study. The data were collected for three different samples:

Sample 1: Non-psychiatric control sample of young adults (college and vocational school students, $n=849$ ) who volunteered to participate for research credits. The recruitment was performed in 4 educational institutions in Moscow ( $n=522)$ and in 5 educational institutions in other Russians regions $(n=327)$, the consent rate was above 0.7. A part of the participants $(n=652)$ used paper and pen version, other participants used web-based survey forms and completed them in class settings. 57 participants from Sample 1 failed to provide the answers to all the questions and were excluded from further analyses, reducing the number of the accepted participants for Sample to 794. Three participants failed to report their gender, therefore the total number of participants from the sample is greater than the sum of female $(n=504)$ and male $(n=287)$ participants.

Sample 2: A sample with a higher than normal ratio of adults with ASD (total $n=509$ ) was recruited using snowball sampling by targeting autism-related communities to ensure a higher than normal ratio of participants with ASD. To provide the initial estimates of the sensitivity of the RAADS-14 Rus in this study we relied on self-reported ASD diagnosis, reportedly established in clinical settings $(n=49)$, similarly to another recent study assessing the RAADS14 properties for a different national sample ${ }^{30}$; for a smaller subset of the participants that gave their consent $(n=13)$ it was further verified by ADOS-2. All the participants in this sample used web-based survey forms and completed them at their convenience.

Sample 3: An additional web-based sample was recruited using snowball sampling (total $n=364)$ to provide the data for evaluating possible relations between the autism traits measured by the RAADS-14 Rus and the Big Five 
personality traits. All the participants in this sample used web-based survey forms and completed them at their convenience.

After all the exclusions the data from a total of 1667 participants used for further analyses. The data collection was anonymous for all the participants but the participants from samples 2 and 3 were suggested to provide their emails (this was optional and the emails were used for the sole purpose of providing the feedback with participant's personal RAADS-14 Rus scores and general follow-up for the study and were later removed from the resulting datasheet). For detailed age and gender statistics for all the samples see Table 2.

Table 2. General characteristics of the study samples.

\begin{tabular}{|c|c|c|c|c|c|}
\hline Sample & & Age Mean & Age SD & Mean RAADS-14 Score & RAADS-14 Score SD \\
\hline \multicolumn{6}{|l|}{ Sample I } \\
\hline & Women $(n=504)$ & 2.3 & 5.4 & 14.3 & 7.4 \\
\hline & Men $(n=287)$ & 199 & 3.8 & 13.4 & 7.7 \\
\hline Total $(n=794)$ & & 2.1 & 4.9 & 13.9 & 7.5 \\
\hline \multicolumn{6}{|l|}{ Sample II } \\
\hline & Women $(n=331)$ & 35.2 & 1.0 & 21.5 & 11.8 \\
\hline & Men $(n=128)$ & 36.3 & 11.8 & 21.3 & 1.7 \\
\hline & Other $(n=50)$ & 27.1 & 8.6 & 3.92 & 8.14 \\
\hline Total $(n=509)$ & & 34.7 & 1.7 & 22.36 & 11.57 \\
\hline \multicolumn{6}{|l|}{ Sample III } \\
\hline & Women $(n=263)$ & 31.7 & 1.1 & 18.5 & 9.2 \\
\hline & Men $(n=85)$ & 32.4 & 9.5 & 16.1 & 8.2 \\
\hline & Other $(n=16)$ & 33.0 & 9.0 & 24.3 & 9.0 \\
\hline Total $(n=364)$ & & 31.9 & 9.9 & 18.22 & 9.12 \\
\hline
\end{tabular}

\section{Due procedure statement}

All the research procedures were carried out in accordance with the American Psychological Association Ethical Principles of Psychologists and Code of Conduct ${ }^{39}$ and American Psychiatric Association Principles of Medical Ethics ${ }^{40}$. All the participants provided their informed consent before completing the questionnaire and were free to opt out at any stage of the study. All the aspects of the data collection and treatment reported in the present article were approved by the Pushkin Institute research ethics committee.

\section{Materials}

RAADS-14 Rus. The original 14 items of the RAADS-14, as published in ${ }^{8}$, were translated from English into Russian independently by a team of three certified translators, all of them had a prior experience with ASD-related problems of at least 2 years. A consensus version was composed collegially by the three translators, an impartial editor, and a member of ASD community having more than 5 years of consulting experience with ASD-related problems. Back- 
translation performed independently by two English native speakers unfamiliar to the original revealed no meaningful disagreement with the original version. As in the original RAADS-14, all the items were scored on a fourpoint Likert scale (ranging from 0 to 3 ) indicating duration of each symptom ( 3 = 'true now and when I was young', $2=$ 'true only now', $1=$ 'true only when I was younger than 16 ' and $0=$ 'never true'). The item scores were summed to produce the total score (for general total score statistics by samples see Table 1). The Russian version of the form is provided in Supplementary information (S1 Table).

The Big Five personality model. To assess the Big Five personality factors we used a Russian version of the NEO-FFI 41 . This questionnaire is reasonably brief (50 items) and its factor structure has been consistently replicated for different Russian-speaking samples ${ }^{42,43}$.

\section{Data analysis}

Reliability and the factor structure. To evaluate the reliability and the factor structure of the RAADS-14 Rus we pooled the participants from all the samples resulting in a total of 1667 participants. Cronbach's a was used to assess the reliability of the scale. In order to assess whether the factor structure of the RAADS-14 Rus was equivalent to the factor structure of the original version, confirmatory factor analysis (CFA) was performed using a single-order threefactor model reported in the original validation study. Weighted least-squares with mean and variance (WLSMV) procedure was used to estimate the model. The goodness of model fit was tested by calculating CFI (comparative fit index) and root-mean-square-error of approximation (RMSEA).

\section{Demographics and correlation analyses.}

Age and gender effects were assessed separately for all the samples due to prominent differences in the demographics and clinical characteristics of the samples. A Kolmogorov-Smirnov test was performed for total RAADS-14 Rus for the pooled sample revealing that the data do not have a normal distribution ( $n=1667$, Mean=17,42, $S D=9,96, D=.07, p<.001)$. Due to the non-normal nature of the data, all the group-related differences were assessed with Kruskal-Wallis ANOVAs and Mann-Whitney U-tests. Spearman's rank-order correlations were used for subscale cross-correlations and for correlations with the Big Five factor scores.

Screening properties. The discriminatory power was assessed using a receiver operating characteristic (ROC) curve, estimating sensitivity (the rate of true positives for the ASD sample), specificity (1 minus the rate of false positives for the non-psychiatric control sample), and the area under the curve (AUC) as a measure of the discriminatory power (an AUC greater than 0.7 is generally considered satisfactory) ${ }^{44}$.

Statistical analysis. All the statistical analyses were performed using Statistica 10, IBM SPSS Statistics 23, and Mplus 8.2 software ${ }^{45}$. Bonferroni corrections for multiple comparisons were used where appropriate.

\section{Data availability}

All data generated or analyzed during this study were in anonymized and are included in this published article (and its Supplementary Information files).

\section{Declarations}

\section{Funding and Acknowledgements}

The reported study was funded by RFBR according to the research project № 18-00-01670 (18-00-01616).

Page 10/17 
The authors would like to thank Antonina Steinberg for her help with the RAADS-14 translation and advice on issues related to Russian autism community, and to thank Anna Kravchenko, Elvira Budaeva, Maria Ivanova and Aleksey Semirechenko for their help in data collection and analysis.

\section{Authors contributions}

I.S.: study concept and design, data acquisition, data preparation, manuscript revision, K.V.: study concept and design, data analysis., E.S.: data acquisition, S.F.: data acquisition, G.P.: study concept and design, manuscript revision, A.V.: study concept and design, data analysis, manuscript draft and further revision

\section{Competing interests}

The authors declare no competing interests.

\section{References}

1. American Psychiatric Association. Diagnostic and Statistical Manual of Mental Disorders. Arlington (2013). doi:10.1176/appi.books.9780890425596.744053

2. Keyes, K. M. et al. Cohort effects explain the increase in autism diagnosis among children born from 1992 to 2003 in California. Int. J. Epidemiol.41, 495-503 (2012).

3. National Audit Office. Supporting people with autism through adulthood. (2009).

4. Kim, Y.-K. S. et al. Prevalence of Autism Spectrum Disorders in a Total Population Sample. Am. J. Psychiatry168, 904-912 (2011).

5. Brugha, T. S. et al. Epidemiology of autism in adults across age groups and ability levels. Br. J. Psychiatry209, 498-503 (2016).

6. Lai, M. C. \& Baron-Cohen, S. Identifying the lost generation of adults with autism spectrum conditions. The Lancet Psychiatry2, 1013-1027 (2015).

7. Lugo-Marín, J. et al. Prevalence of psychiatric disorders in adults with autism spectrum disorder: A systematic review and meta-analysis. Res. Autism Spectr. Disord.59, 22-33 (2019).

8. Eriksson, J. M., Andersen, L. M. \& Bejerot, S. RAADS-14 Screen: validity of a screening tool for autism spectrum disorder in an adult psychiatric population. Mol. Autism4, 49 (2013).

9. Baron-Cohen, S., Wheelwright, S., Skinner, R., Martin, J. \& Clubley, E. The Autism-Spectrum Quotient (AQ): Evidence from Asperger Syndrome/High-Functioning Autism, Males and Females, Scientists and Mathematicians. J. Autism Dev. Disord.31, 5-17 (2001).

10. Baghdadli, A., Russet, F. \& Mottron, L. Measurement properties of screening and diagnostic tools for autism spectrum adults of mean normal intelligence: A systematic review. Eur. Psychiatry44, 104-124 (2017).

11. Ritvo, R. A. et al. The Ritvo Autism Asperger Diagnostic Scale-Revised (RAADS-R): A Scale to Assist the Diagnosis of Autism Spectrum Disorder in Adults: An International Validation Study. J. Autism Dev. Disord.41, 1076-1089 (2011).

12. Nishiyama, T. et al. Comprehensive Comparison of Self-administered Questionnaires for Measuring Quantitative Autistic Traits in Adults. J. Autism Dev. Disord.44, 993-1007 (2014).

13. Horwitz, E. H. et al. Clinical assessment of ASD in adults using self- and other-report: Psychometric properties and validity of the Adult Social Behavior Questionnaire (ASBQ). Res. Autism Spectr. Disord.24, 17-28 (2016). 
14. Andersen, L. M. J. et al. The Swedish Version of the Ritvo Autism and Asperger Diagnostic Scale: Revised (RAADS-R). A Validation Study of a Rating Scale for Adults. J. Autism Dev. Disord.41, 1635-1645 (2011).

15. Sizoo, B. B. et al. Predictive validity of self-report questionnaires in the assessment of autism spectrum disorders in adults. Autism19, 842-849 (2015).

16. Eriksson, J. M., Andersen, L. M. \& Bejerot, S. RAADS-14 Screen: validity of a screening tool for autism spectrum disorder in an adult psychiatric population. Mol. Autism4, 49 (2013).

17. Mukaetova-Ladinska, E. B., Simashkova, N. V., Mukaetova, M. S., Ivanov, M. V. \& Boksha, I. S. Autism spectrum disorders in children and adults: the experience of reserches from different countries. Zhurnal Nevrol. i psikhiatrii im. S.S. Korsakova118, 92 (2018).

18. Simashkova, N. V. [Effecrive pharmacotherapy and rehabilitation of patients with autistic spectrum disorder]. Eff. Pharmacother. 44-50 (2011).

19. Nesterova, A. A. \& Khitryuk, V. V. STIGMATIZATION AND PREJUDICE TOWARDS PARENTS OF CHILDREN WITH AUTUISTIC SPECTRUM DISORDERS. Bull. Moscow State Reg. Univ. 50-61 (2018). doi:10.18384/2310-72352018-4-50-61

20. Borodina, L. G. [Changing the diagnosis of ASD after the age of 18: an opinion of a psychatrist]. Autism Dev. Disord.3, 41-43 (2015).

21. Agofonov, I. The Ministry of health recognized the existence of adults with childhood autism. (2017).

22. Sorokin, A. B. \& Davydova, E. Y. Autism Diagnostic Evaluation Schedule(ADOS-2) for Evaluation of Behavior and Communication in Toddlers with Concern of Autism Spectrum Disorder. Autism Dev. Disord.15, 38-44 (2017).

23. Lord, C., Rutter, M., DiLavore, P. C. \& Risi, S. Plan diagnosticheskogo obsledovaniya pri autizme. Izdanie vtoroe: rukovodstvo [Autism Diagnostic Observation Schedule. Second Edition: Manual]. (Western Psychological Services; Giunti O.S., 2016).

24. Aspergers.ru. Tests for self-diagnosis (In Russian). Available at: https://aspergers.ru/tests. (Accessed: 5th October 2020)

25. Goldberg, L. R. The structure of phenotypic personality traits. Am. Psychol.48, 26-34 (1993).

26. Lodi-Smith, J., Rodgers, J. D., Cunningham, S. A., Lopata, C. \& Thomeer, M. L. Meta-analysis of Big Five personality traits in autism spectrum disorder. Autism23, 556-565 (2019).

27. Schwartzman, B. C., Wood, J. J. \& Kapp, S. K. Can the Five Factor Model of Personality Account for the Variability of Autism Symptom Expression? Multivariate Approaches to Behavioral Phenotyping in Adult Autism Spectrum Disorder. J. Autism Dev. Disord.46, 253-272 (2016).

28. Tabachnick, B. G. \& Fidell, L. S. Using Multivariate Statistics. (Pearson Education, 2013).

29. Steiger, J. H. Understanding the limitations of global fit assessment in structural equation modeling. Pers. Individ. Dif. (2007). doi:10.1016/j.paid.2006.09.017

30. Kember, S. M. \& Williams, M. N. Autism in Aotearoa: Is the RAADS-14 a Valid Tool for a New Zealand Population? Eur. J. Psychol. Assess. (2020). doi:10.1027/1015-5759/a000598

31. Mayer, J. L. The Relationship Between Autistic Traits and Atypical Sensory Functioning in Neurotypical and ASD Adults: A Spectrum Approach. J. Autism Dev. Disord.47, 316-327 (2017).

32. Barrett, S. L., Uljarević, M., Jones, C. R. G. \& Leekam, S. R. Assessing subtypes of restricted and repetitive behaviour using the Adult Repetitive Behaviour Questionnaire-2 in autistic adults. Mol. Autism9, 58 (2018).

33. Cooper, K., Smith, L. G. E. \& Russell, A. J. Gender Identity in Autism: Sex Differences in Social Affiliation with Gender Groups. J. Autism Dev. Disord.48, 3995-4006 (2018). 
34. Kristensen, Z. E. \& Broome, M. R. Autistic Traits in an Internet Sample of Gender Variant UK Adults. Int. J. Transgenderism16, 234-245 (2015).

35. Nobili, A. et al. Autistic Traits in Treatment-Seeking Transgender Adults. J. Autism Dev. Disord.48, 3984-3994 (2018).

36. Lodi-Smith, J., Rodgers, J. D., Cunningham, S. A., Lopata, C. \& Thomeer, M. L. Meta-analysis of Big Five personality traits in autism spectrum disorder. Autism23, 556-565 (2019).

37. Schwartzman, B. C., Wood, J. J. \& Kapp, S. K. Can the Five Factor Model of Personality Account for the Variability of Autism Symptom Expression? Multivariate Approaches to Behavioral Phenotyping in Adult Autism Spectrum Disorder. J. Autism Dev. Disord.46, 253-272 (2016).

38. Cherednichenko, G. A. Sistema obrazovania i puti molodezhi [Education system and the ways of the youngs]. in Rossiaya reformiruyuchshayasya: ezhegodnik: vyp 15 [Reforming Russia annually: Issue 15] (ed. Gorshkov, M. K.) 175-198 (Novyy Khronograph, 2017).

39. American Psychological Association. Ethical Principles of Psychologists and Code of Conduct. (2017).

40. American Psychiatric Association. The Principles of Medical Ethics With Annotations Especially Applicable to Psychiatry. (2013).

41. Bodunov, M. V. \& Biryukov, S. D. Big 5: Five-Factor Inventory. Adapted and reproduced by special permission of the Publisher. Psychological Assessment Resources from the NEO Five Factor Inventory by P. Costa, R. McCrae. Form S. (Institute of Psychology RAS, 1989).

42. Novikova, I. A., Novikov, A. L., Obidina, N. V. \& Shlyakhta, D. A. Psychological predictors of managerial performance in the conditions of instability of the Russian economy. Int. J. Environ. Sci. Educ.11, 10863-10874 (2016).

43. Novikova, I. A., Novikov, A. L., Gridunova, M. V. \& Zamaldinova, G. N. INTERCULTURAL COMPETENCE PROFILES IN RUSSIAN UNIVERSITY STUDENTS. Rudn J. Psychol. Pedagog.14, 326-338 (2017).

44. Fawcett, T. An introduction to ROC analysis. Pattern Recognit. Lett.27, 861-874 (2006).

45. Muthén, L. K. \& Muthén, B. Mplus. The comprehensive modelling program for applied researchers: user's guide. (2016).

\section{Figures}




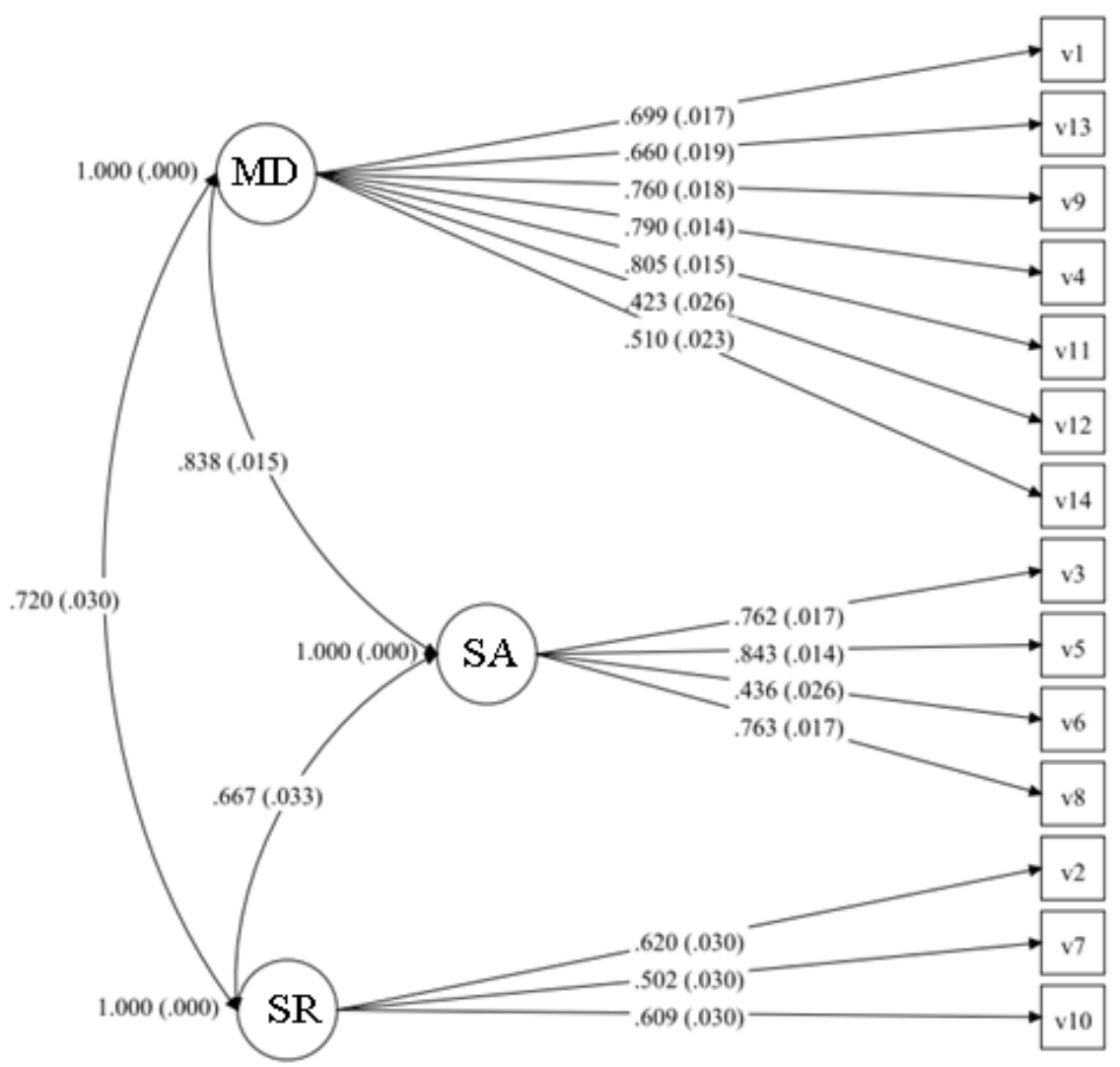

Figure 1

The path diagram for the RAADS-14 Rus with factor loadings and covariances. MD - Mentalizing deficits, SA Social anxiety, SR - Sensory Reactivity 


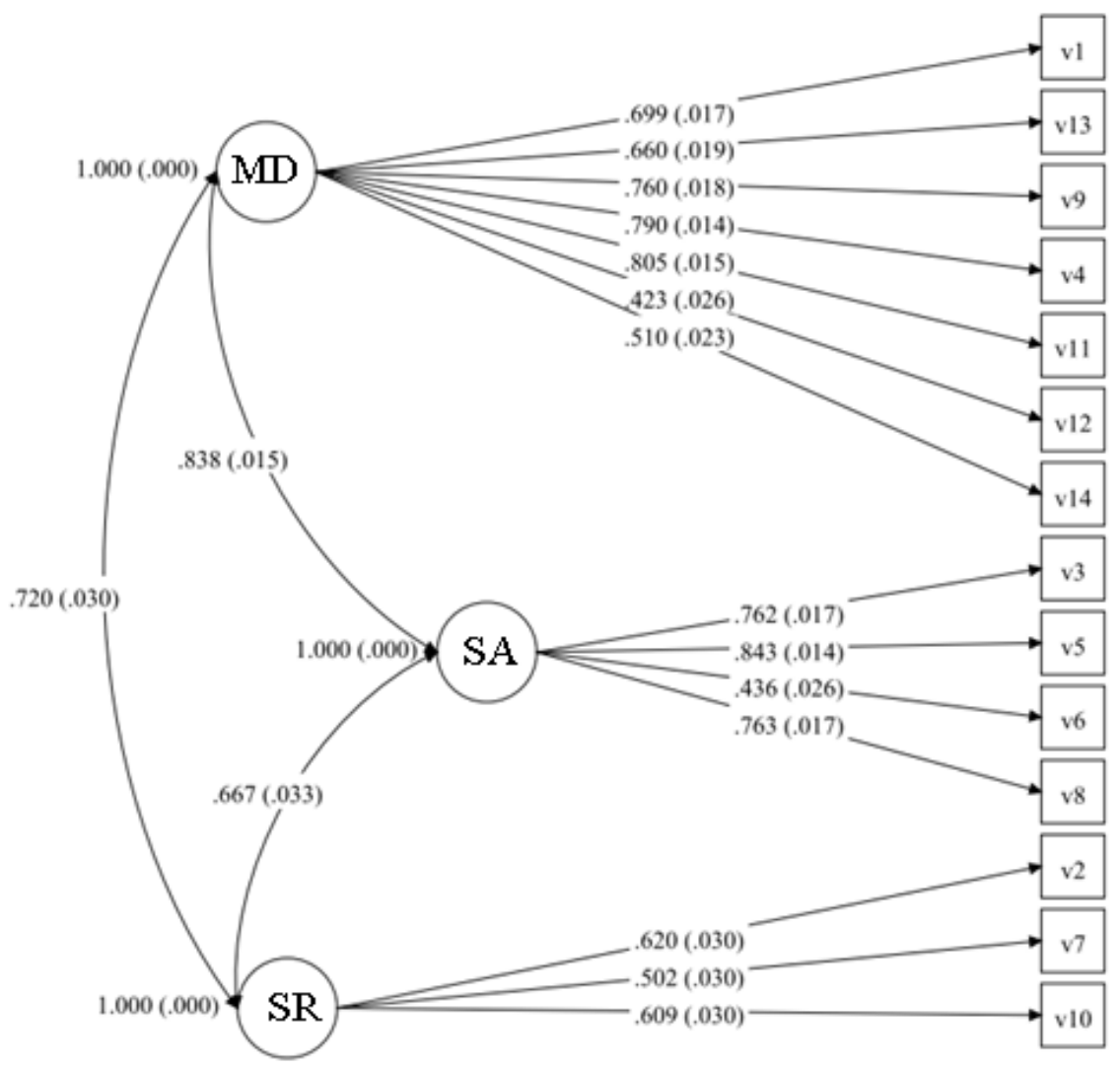

Figure 1

The path diagram for the RAADS-14 Rus with factor loadings and covariances. MD - Mentalizing deficits, SA Social anxiety, SR - Sensory Reactivity

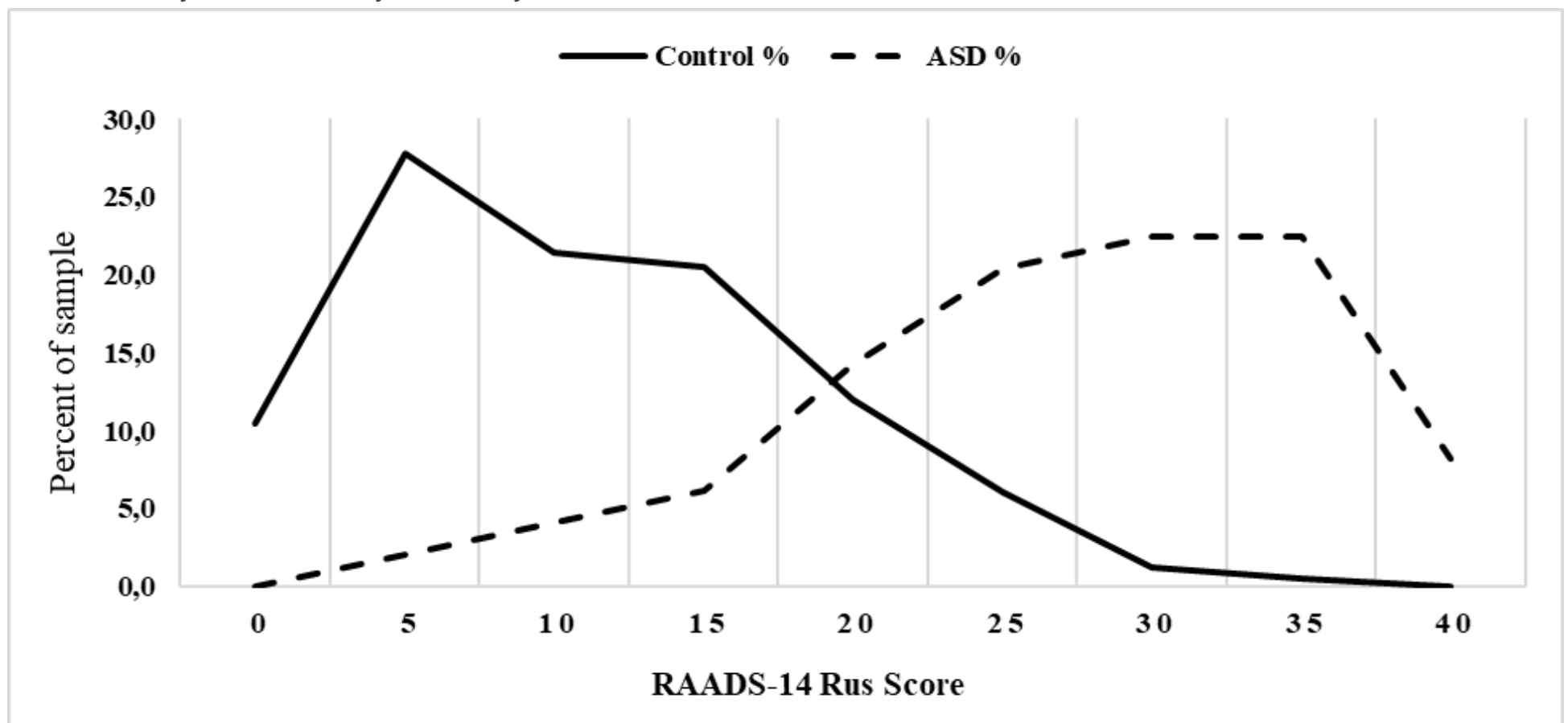

Figure 2 
The distribution of the RAADS-14 Rus total scores for non-psychiatric young adults and ASD participants.

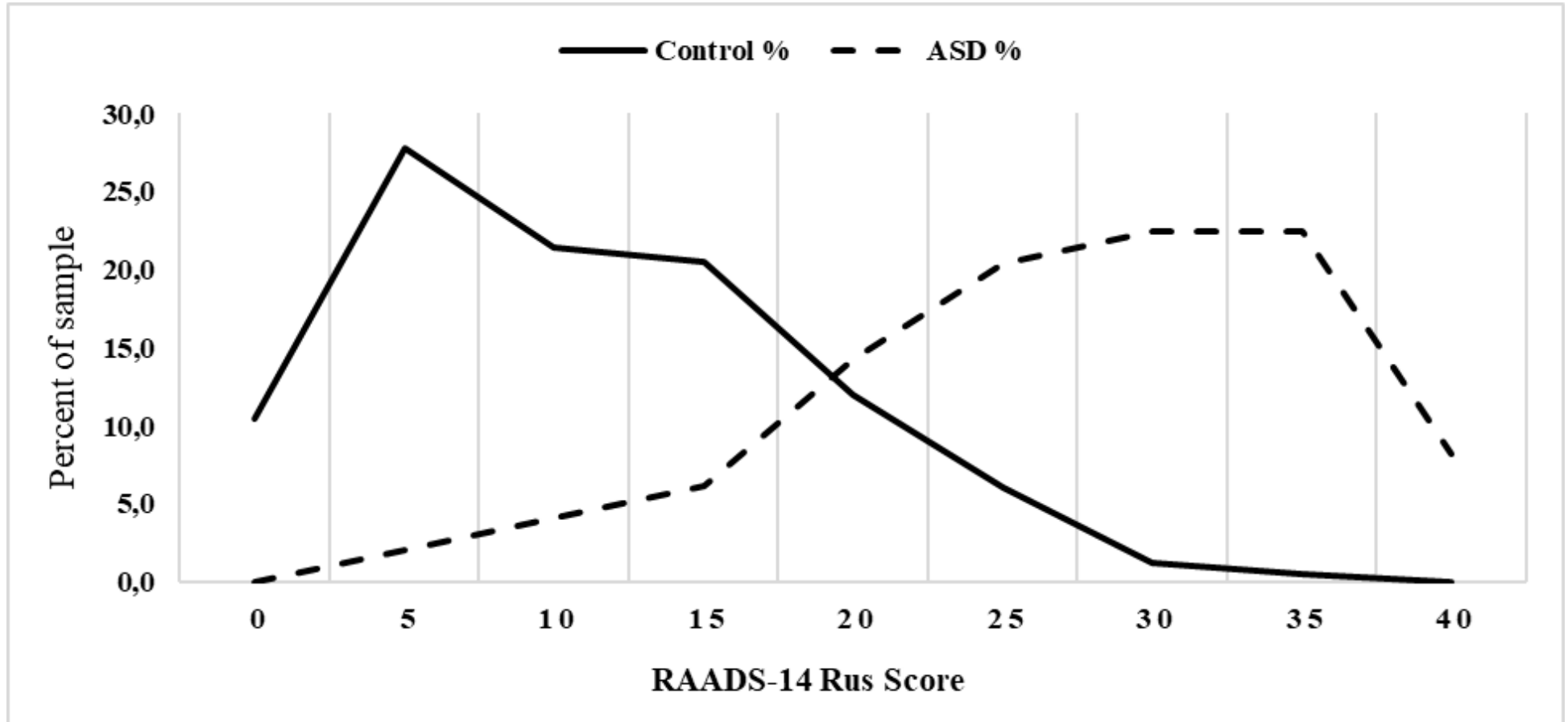

Figure 2

The distribution of the RAADS-14 Rus total scores for non-psychiatric young adults and ASD participants.

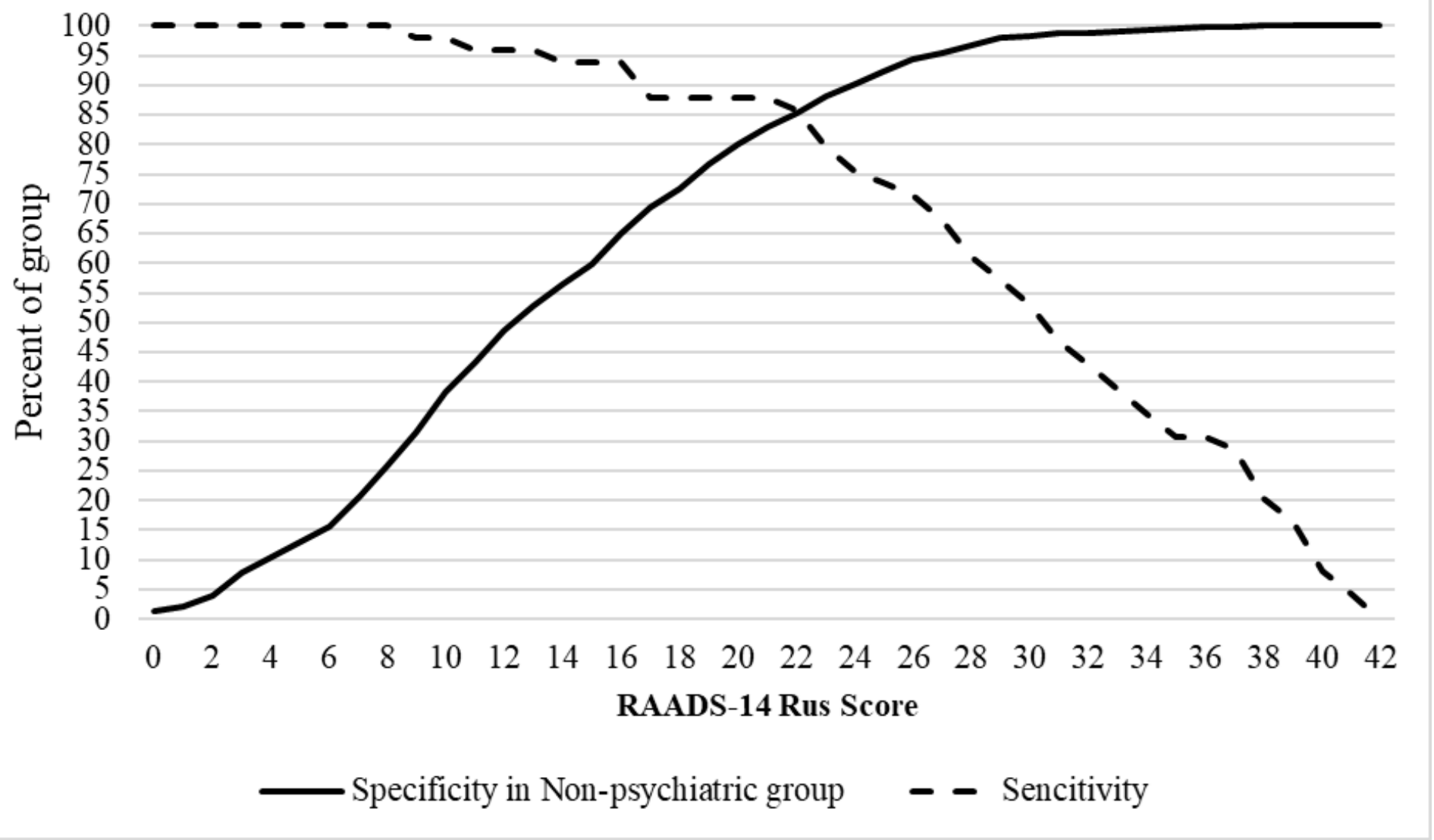

Figure 3 
Operating characteristics of the RAADS-14 Rus.

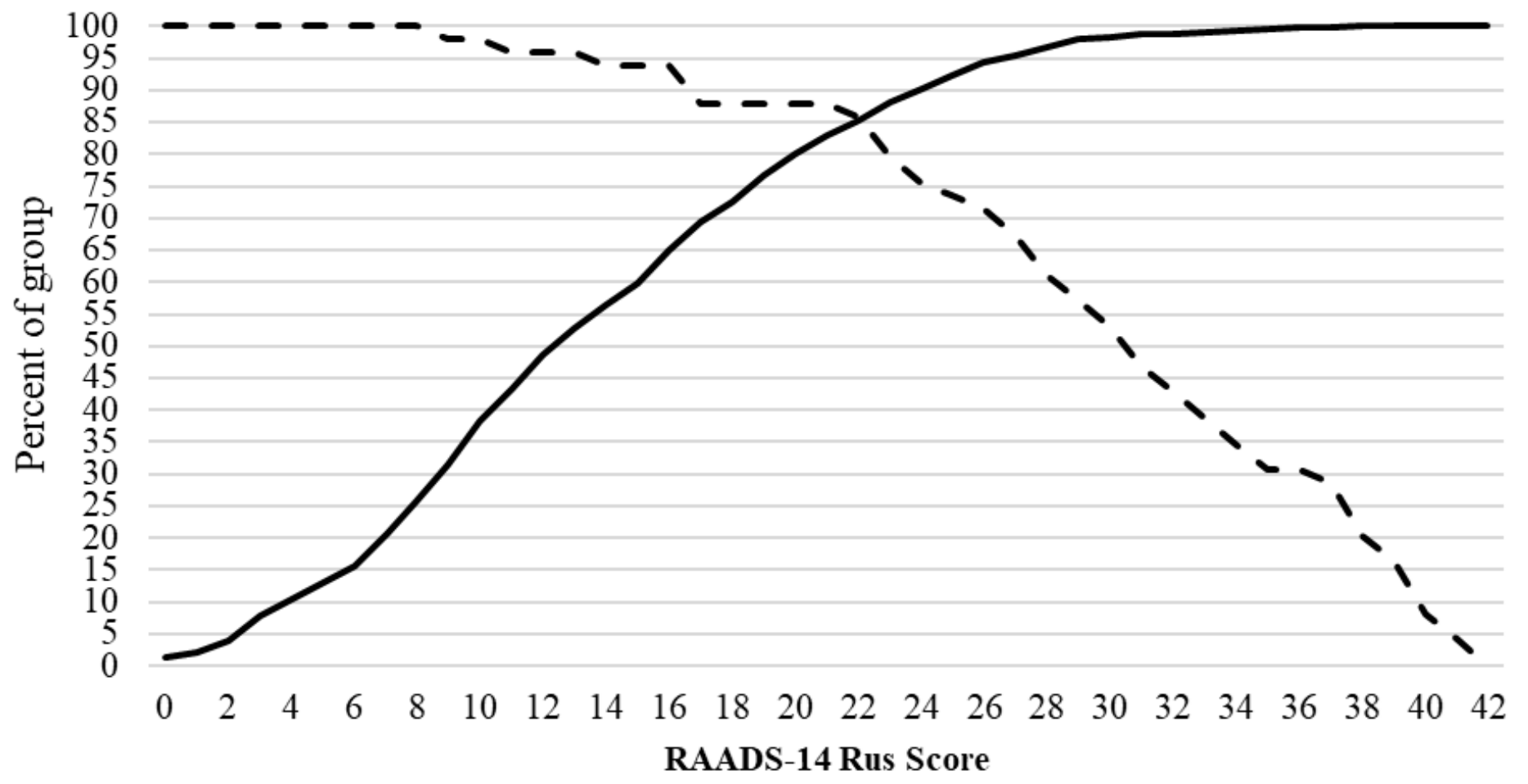

— Specificity in Non-psychiatric group _ - Sencitivity

Figure 3

Operating characteristics of the RAADS-14 Rus.

\section{Supplementary Files}

This is a list of supplementary files associated with this preprint. Click to download.

- S1Appendix.pdf

- S1Appendix.pdf

- RAADS14RUSS1Appendix.pdf

- RAADS14RUSS1Appendix.pdf

- RAADS14Rus1667S2.xIsx

- RAADS14Rus1667S2.xIsx 